\title{
Sensitivity of Streptomycetes to Antibiotics as a Taxonomic Character
}

\author{
By S. T. WILLIAMS \\ Hartley Botanical Laboratories, University of Liverpool
}

(Accepted for publication 24 August 1966)

\begin{abstract}
SUMMARY
A procedure for testing the sensitivity of streptomycetes to antibiotics is described. Eight antibiotics, at various concentrations, were incorporated into filter-paper discs and by selection of suitable concentrations results of diagnostic value were obtained. Streptomycetes previously grouped together by using other criteria had identical or very similar antibiotic sensitivity patterns. It is considered that the reactions of streptomycetes to a range of antibiotics would be of value for description of species and studies of overall similarity.
\end{abstract}

\section{INTRODUCTION}

The ability of species of streptomycetes to produce a certain antibiotic or antibiotics is usually recorded in their descriptions. Krassilnikov $(1958,1960)$ emphasized the importance of antibiotic production as a taxonomic character and considered that it was one of the most stable attributes of streptomycetes; other workers, such as Waksman (1961), did not regard it as a significant criterion. Its value is questioned because some species can produce several different antibiotics and different species can sometimes produce the same one. In contrast, the sensitivity of streptomycetes to antibiotics has not often been considered in taxonomic studies, although Waksman (1961) included it in a list of characters which he regarded as important in the taxonomy of the genus Streptomyces.

Filter-paper discs impregnated with antibiotics at known concentrations have been used to test the sensitivity of streptomycetes and other actinomycetes. Waksman \& Lechevalier (1953) found nearly all the streptomyces species they tested were sensitive to the antibacterial antibiotics used, but none was inhibited by antifungal antibiotics. Okami (1956), in a study of strains in the Streptomyces lavendulae group, tested their sensitivity to five antibiotics, each incorporated into paper discs at a concentration of $100 \mu \mathrm{g} . / \mathrm{ml}$. The results allowed a distinction between some of the closely related strains of this group. By the same method Okami, Hashimoto \& Suzuki (1960) tested the reactions of a wide range of streptomycetes to 22 antibiotics. They noted that antibiotic producers generally resisted their own antibiotics and showed a characteristic spectrum of sensitivity. It was considered that the test could be used as a guide to the identification of species of the genus Streptomyces. Burkholder, Sun, Anderson \& Ehrlich (1954), considering criteria for the description of species in the genus, concluded that antibiotic-sensitivity results could provide useful information for the characterization of strains and perhaps species. The sensitivity of other genera of actinomycetes to antibiotics has occasionally been considered. Lechevalier, Solo- 
torovsky \& McDurmont (1961), in a study of the genus Micropolyspora, included sensitivity to several antibiotics in a range of tests used to describe new species. Similar tests were used by Cross, Lechevalier \& Lechevalier (1963) for the description of Microellobosporia species. In an investigation of overall similarity of actinomycetes, which included many streptomycetes, Hill \& Silvestri (1962) allocated 16 code marks to antibiotic sensitivity tests. Six antibiotics incorporated into paper discs at various concentrations were used. The results obtained with four of the antibiotics were considered to be of diagnostic significance. Those obtained with neomycin at $125 \mu \mathrm{g} . /$ $\mathrm{ml}$. were used in the construction of a diagnostic key. These authors considered that a similar reaction by different strains to an antibiotic indicated that they shared part or all of a limiting metabolic pathway.

Methods other than impregnated paper discs have occasionally been used to test the sensitivity of actinomycetes. An investigation of the overall similarity of oral actinomycetes, mainly in the genus Actinomyces, was made by Melville (1965). The reactions of strains to five antibiotics, each at a concentration of $10 \mathrm{mg} . / 100 \mathrm{ml}$, was tested by placing antibiotic solutions in ditches cut in the solid medium. All strains were inhibited by each antibiotic, so that the results were of no diagnostic value. Krassilnikov \& Agre (1964) cross-streaked known antibiotic-producing strains of streptomycetes with Thermopolyspora strains and noted the inhibition of the latter. Strains previously grouped together on their morphological characteristics generally had similar patterns of inhibition. A similar approach was made by Pridham \& Lyons (1965), who examined the sensitivity of streptomycetes to streptomycin by crossstreaking them with a Streptomyces griseus strain known to produce this antibiotic.

Although sensitivity of streptomycetes to antibiotics has occasionally been used as a taxonomic criterion, little information about its reliability or significance is available. The present work was designed to outline a testing procedure, examine its reliability and assess the taxonomic significance of the results which it provided.

\section{METHODS}

Culture medium. All tests were made by using a glycerol + nitrate medium of composition (g./1.): glycerol, 30.0; $\mathrm{NaNO}_{3}, 2 \cdot 0 ; \mathrm{K}_{2} \mathrm{HPO}_{4}, 1 \cdot 0 ; \mathrm{MgSO}_{4} .7 \mathrm{H}_{2} \mathrm{O}, 0 \cdot 5 ; \mathrm{KCl}, 0 \cdot 5$; $\mathrm{FeSO}_{4} .7 \mathrm{H}_{2} \mathrm{O}, 0.01$; Oxoid agar no. 3, 12.0; de-ionized water $1000 \mathrm{ml}$.; after autoclaving the medium was at $\mathrm{pH} 7 \cdot 0$. Shinobu (1958) found that streptomycetes grew well on this medium, glycerol being a good source of carbon and $\mathrm{NaNO}_{3}$ a generally available source of nitrogen. It also has the advantage of being clear when solidified, thus facilitating the reading of results of antibiotic-sensitivity tests.

Antibiotics. The antibiotics used were streptomycin sulphate (Glaxo), erythromycin (Lilly), neomycin sulphate (Boots), polymyxin B sulphate (Burroughs Wellcome), chlortetracycline hydrochloride (Cyanamid), chloramphenicol (Allen and Hanburys), viomycin sulphate (Dista), sodium novobiocin (Glaxo). Solutions of chloramphenicol were made in de-ionized water and sterilized by autoclaving. All other antibiotics were obtained as sterile powders and solutions were made in sterile water. Solutions were used immediately after their preparation to soak the filter-paper discs.

Preparation of spore suspensions. The organisms were grown on slopes of oatmeal agar (Waksman, 1961) at $25^{\circ}$ for 14 days. Spores on the mature cultures were removed with an inoculation loop to $5 \mathrm{ml}$. sterile water. The suspensions were used within $1 \mathrm{hr}$ of preparation to seed medium. Spore suspensions were shaken vigorously and 
$0.01 \mathrm{ml}$. samples were added to $15 \mathrm{ml}$. samples of melted medium at $45^{\circ}$, which was then poured into dishes and allowed to set.

Preliminary examination of testing procedure. Three methods for testing sensitivity of streptomycetes to antibiotics were examined.

(i) Antibiotics were incorporated into the culture medium and test strains were streaked on to the surface. Growth of streptomycetes on medium containing antibiotics was then compared with that on control medium without antibiotics. A major difficulty was encountered when reading the results for in many cases the growth of streptomycetes on medium containing antibiotics was uneven.

(ii) Antibiotics incorporated in Oxoid 'Multodisks' were also used. Multodisks were laid on the surface of medium seeded with streptomycetes. The results indicated that the concentrations of antibiotics in these discs were too high. Many of the antibiotics inhibited all test strains and inhibition zones were often so large that interference occurred between zones around adjacent discs.

(iii) The antibiotics listed above were incorporated into filter-paper discs. The results of this experiment indicated that it was the most satisfactory of the methods and it was selected for more detailed appraisal.

Incorporation of antibiotics into filter-paper discs. Discs of filter paper (Whatman no. 1), $5 \mathrm{~mm}$. diameter, were soaked in antibiotic solutions at chosen concentrations for $2 \mathrm{~min}$. The discs were then removed to sterile dishes and rapidly freeze-dried under low vacuum $\left(0 \cdot 2\right.$ torr) over $\mathrm{P}_{2} \mathrm{O}_{5}$ for $90 \mathrm{~min}$. The dried discs were stored in sealed containers at $4^{\circ}$ until use.

Selection of a suitable period of incubation. Experiments were made to select an incubation period after which clear stable inhibition zones could be obtained. Fourteen streptomycetes were tested against antibiotics in filter-paper discs. Plates were incubated at $25^{\circ}$ for 14 days, the presence of inhibition zones being noted at 2-day intervals.

Selection of suitable concentrations of antibiotics. Experiments were made to select antibiotic concentrations which would inhibit some, but not all the streptomycetes used, thus providing results of diagnostic value. After preliminary tests with fourteen streptomycetes, the following concentrations were selected: streptomycin sulphate, $3 \mu \mathrm{g} . / \mathrm{ml}$.; erythromycin, $150 \mu \mathrm{g} . / \mathrm{ml}$.; neomycin sulphate, $3 \mu \mathrm{g} . / \mathrm{ml}$.; polymyxin B sulphate, $60 \mu \mathrm{g} . / \mathrm{ml}$; chlortetracycline hydrochloride, $50 \mu \mathrm{g} . / \mathrm{ml}$.; chloramphenicol, $300 \mu \mathrm{g} . / \mathrm{ml}$.; viomycin sulphate, $3 \mu \mathrm{g} . / \mathrm{ml}$.; sodium novobiocin, $100 \mu \mathrm{g} . / \mathrm{ml}$. (values expressed refer to wt of salt used).

Discs soaked in antibiotic solutions at these concentrations were then tested against 76 isolates, the presence and size of inhibition zones after 7 days at $25^{\circ}$ being noted.

Assessment of the taxonomic significance of the results. After selection of a suitable testing procedure and the standardization of the conditions for its application, the taxonomic value of the results obtained was examined. Experiments were made to compare the sensitivity patterns of strains which were considered to be identical or similar. Two cultures of each strain were grown on oatmeal agar; from these, two spore suspensions were made and used to prepare two replicate samples of seeded medium. Each replicate was tested against discs soaked in solutions of the antibiotics at chosen concentrations. Results were recorded after incubation for 7 days.

Several streptomyces species were studied by Flaig \& Kutzner (1960). By reference to the colour characteristics of cultures on oatmeal agar, they recognized ten groups. Strains within a group were subgrouped on their morphological characteristics and 
the results of various physiological tests, each subgroup being numbered. Several strains, which had been placed in the same subgroup and therefore considered to be identical, were selected for assessment of the taxonomic significance of antibioticsensitivity tests in the present work. Some named strains not studied by Flaig \& Kutzner, but belonging to species included in their scheme, were also used.

In addition, several unnamed strains were used in these tests. These were isolated from a forest soil at Freshfield, Lancashire, by using the selective isolation method of Williams \& Davies (1965). A preliminary grouping of these isolates was made by using a restricted number of criteria; the procedures used were chosen from those described by Shirling \& Gottlieb (1966).

All colour determinations were made in conditions of standard illumination with strains grown on plates of yeast extract + malt extract agar (Pridham et al. 1956/57) incubated for 21 days at $25^{\circ}$. The colour of the spores en masse was determined by using the colour wheels of Tresner \& Backus (1963). These consisted of colour chips arranged in seven colour series (or wheels). The chip with a colour most nearly matching that of spore mass was noted. The colour of substrate mycelium was determined, after the removal of surplus agar, by comparing the reverse side of colonies with a colour chart composed by Prauser (1964). The tab with a colour nearest to that of the dominant colour of the mycelium was noted. When soluble pigments were present, their colour was assigned to one of the following groups: red, orange, yellow, green, blue, violet. The capacity of isolates to produce a 'melanin' pigment was determined by growing them on slopes of Difco peptone iron agar. The presence or absence of a black pigment in this medium was noted after 4 days at $25^{\circ}$.

On the basis of these results, isolates with similar characteristics were grouped together. The antibiotic sensitivity of strains comprising several of these groups was then studied.

\section{RESULTS}

\section{Selection of a suitable period of incubation}

The results of these tests indicated that little change in the readings occurred after 7 days of incubation. Occasionally very weak inhibition zones became obscured by overgrowth of the streptomycetes during the 7-day period, but most strains needed

Table 1. The reactions of 76 Streptomyces isolates to antibiotics

\begin{tabular}{|c|c|c|c|c|c|c|}
\hline \multirow[b]{2}{*}{ Antibiotics } & \multirow[b]{2}{*}{$\begin{array}{l}\text { Conc. of } \\
\text { antibiotic } \\
\text { solutions } \\
(\mu \mathrm{g} . / \mathrm{ml} .)\end{array}$} & \multirow[b]{2}{*}{$\begin{array}{c}\text { Isolates } \\
\text { not } \\
\text { inhibited } \\
(\%)\end{array}$} & \multirow[b]{2}{*}{$\begin{array}{c}\text { Isolates } \\
\text { with } \\
\text { doubtful } \\
\text { inhibition } \\
(\%)\end{array}$} & \multirow{2}{*}{$\begin{array}{c}\text { Isolates } \\
\text { with } \\
\text { inhibition } \\
\text { zone* } \\
<1 \mathrm{~mm} \text {. } \\
(\%)\end{array}$} & \multirow{2}{*}{$\begin{array}{c}\text { Isolates } \\
\text { with } \\
\text { inhibition } \\
\text { zone } \\
1-4 \mathrm{~mm} \text {. } \\
(\%)\end{array}$} & \multirow[b]{2}{*}{$\begin{array}{c}\text { Isolates } \\
\text { with } \\
\text { inhibition } \\
\text { zone } \\
>4 \mathrm{~mm} . \\
(\%)\end{array}$} \\
\hline & & & & & & \\
\hline Streptomycin sulphate & 3 & 87 & 0 & 3 & 9 & 1 \\
\hline Erythromycin & 150 & 42 & 3 & 8 & 33 & 14 \\
\hline Neomycin sulphate & 3 & 28 & 5 & 25 & 42 & 0 \\
\hline Polymyxin B sulphate & 60 & 61 & 8 & 21 & 10 & 0 \\
\hline Chlortetracyline $\mathrm{HCl}$ & 50 & 50 & 3 & 5 & 42 & 0 \\
\hline Chloramphenicol & 300 & 60 & 5 & 1 & 29 & 5 \\
\hline Viomycin sulphate & 3 & 74 & 0 & 1 & 25 & 0 \\
\hline Novobiocin sodium & 100 & 16 & 1 & 1 & 40 & 42 \\
\hline Overall \% & - & 52 & 3 & 8 & 29 & 8 \\
\hline
\end{tabular}

* Figures given are the radii of the inhibition zones. 


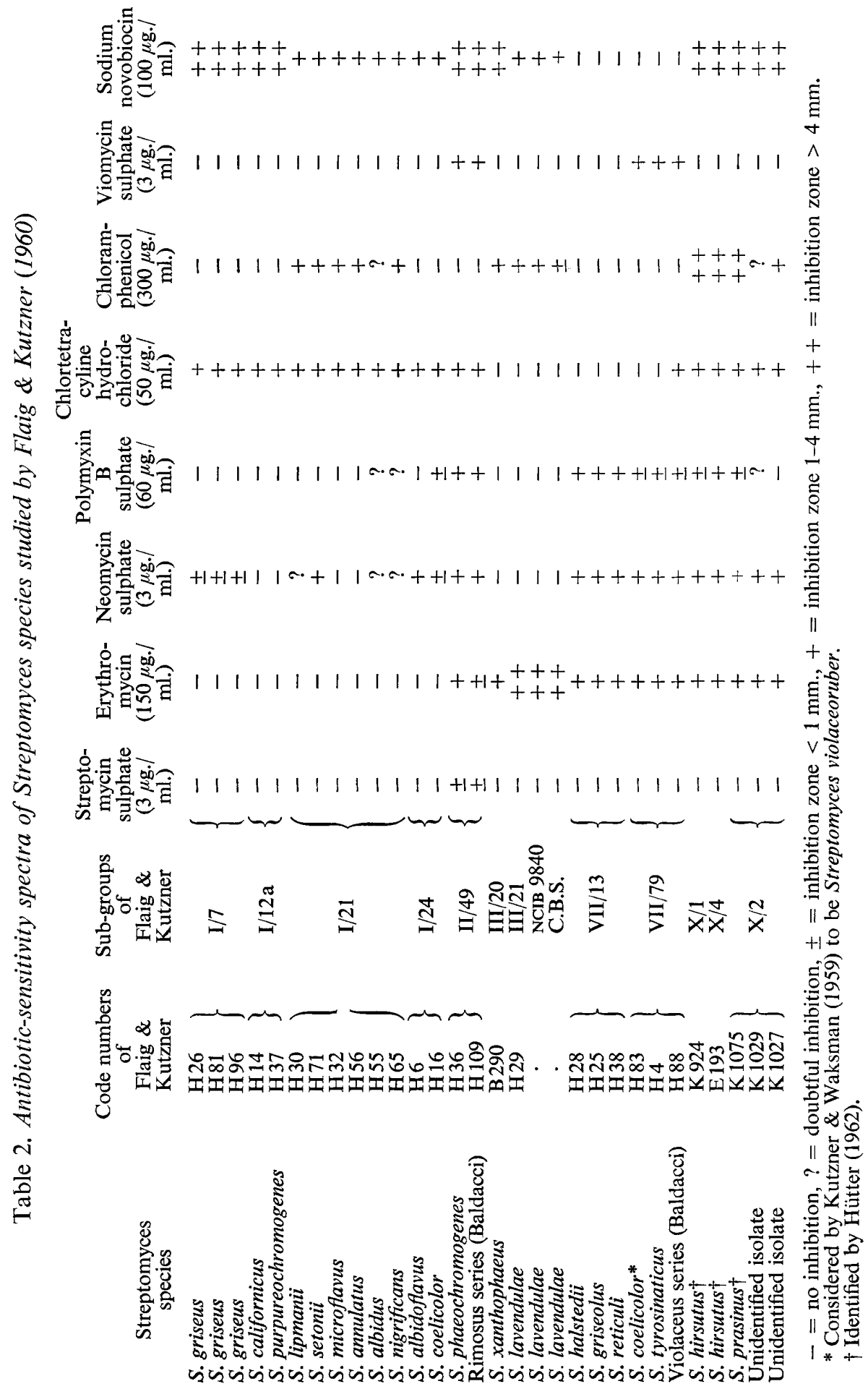


this time to form clearly defined zones. Therefore, in all subsequent experiments, readings were taken after an incubation period of 7 days.

\section{Selection of suitable concentrations of antibiotics}

The results of these tests are given in Table 1. The figures indicate that the antibiotics had a differential effect on the streptomyces isolates. Results of potential diagnostic value were obtained, without reference to small differences in the sizes of inhibition zones. Analysis of the 608 streptomycete/antibiotic interactions showed that in 52\% no inhibition occurred, in $45 \%$ there was inhibition and in $3 \%$ zones were too indistinct for a decision to be reached.

Table 3. Characteristics used to define four groups of Streptomyces isolates from soil

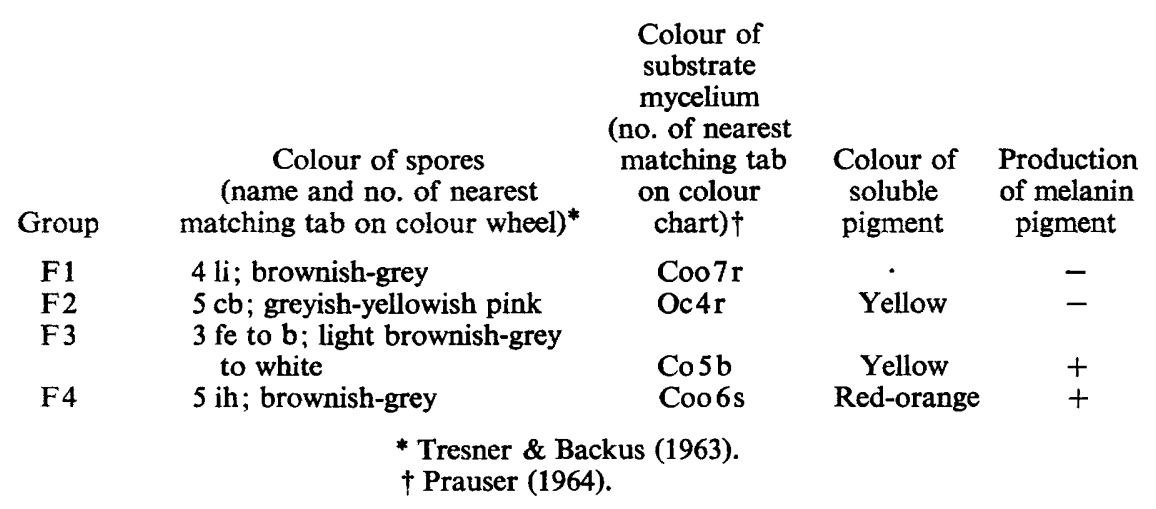

The inhibition zones produced by the eight antibiotics did not share the same features. Sodium novobiocin gave large zones $(42 \%$ over $4 \mathrm{~mm}$. diam.) with distinct margins. Zones produced by polymyxin B sulphate were small but were generally stable, with a clearly defined edge. The majority of zones produced by the other antibiotics were of moderate size, between 1 and $4 \mathrm{~mm}$. diameter. Those produced by streptomycin sulphate, neomycin sulphate and viomycin sulphate had clearly defined edges, but erythromycin, chlortetracycline hydrochloride and chloramphenicol often gave zones with poorly defined limits, making exact measurement difficult.

\section{Assessment of the taxonomic significance of the results}

The results obtained with isolates previously studied by Flaig \& Kutzner (1960) are given in Table 2 . Strains in the same subgroup generally had identical or very similar antibiotic-sensitivity spectra. Identical results were obtained for three Streptomyces griseus strains. Streptomyces californicus and S. purpureochromogenes had identical spectra and differed from $S$. griseus only in their reaction to neomycin sulphate; Waksman (1961) included $S$. californicus in his griseus series. Species in subgroup $I / 21$ had similar spectra, but some differences in reactions to neomycin sulphate and polymixin B sulphate were observed. The reactions of the $S$. lavendulae strains and $S$. xanthophaeus differed only in the size of zone produced; $S$. xanthophaeus has many points of similarity to $S$. lavendulae, being differentiated mainly by its production of a yellow soluble pigment. The strains in subgroup VII/79 all produced 


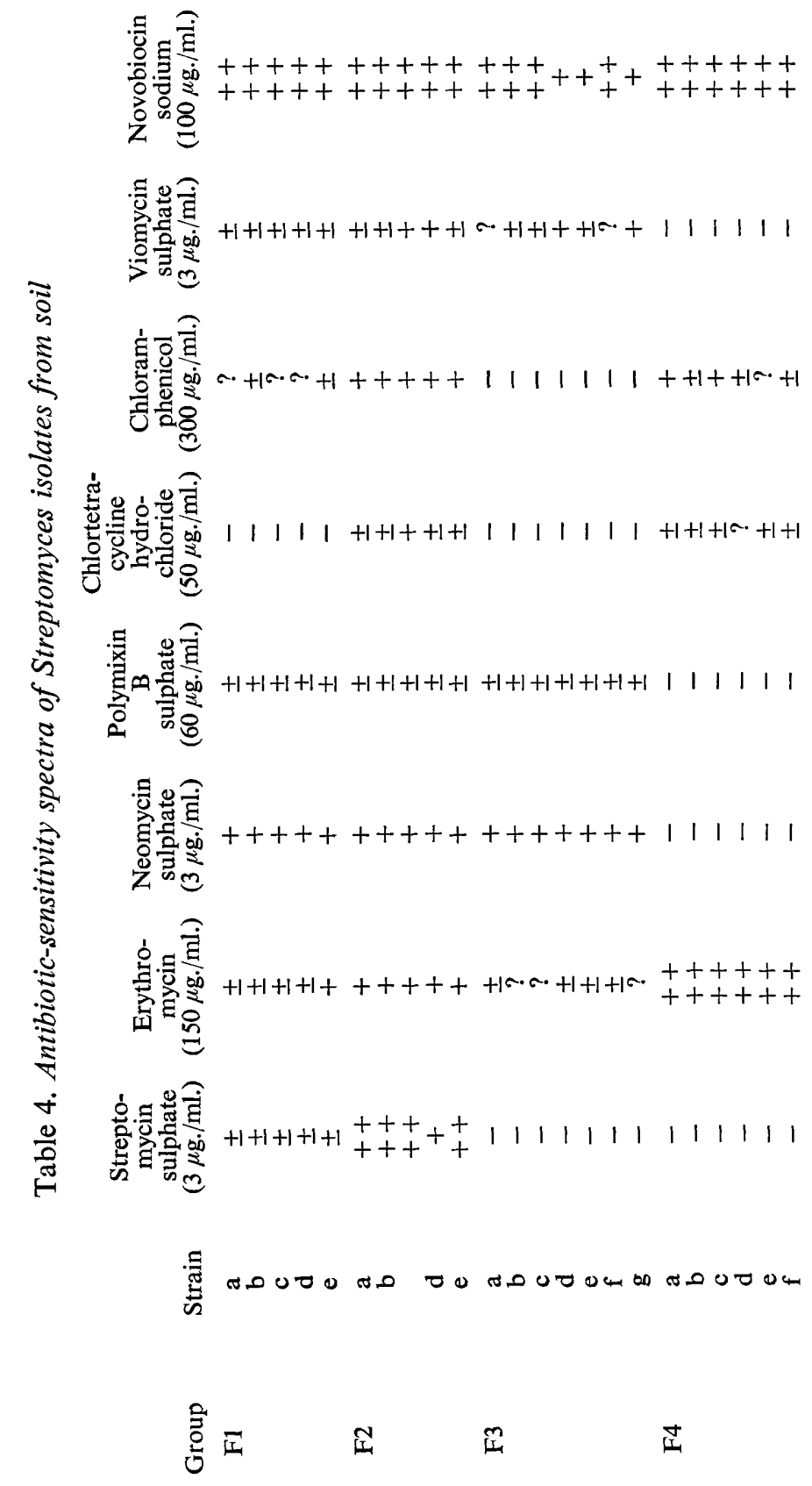


a litmus-like pigment; the strain from Baldacci's 'violaceus' series differed from the others in its reaction to chlortetracycline hydrochloride. All strains in group X, which formed green spores, had a similar reaction. The inhibition patterns of $S$. hirsutus and $S$. prasinus were identical; these two species have many features in common and were distinguished by Hütter (1962) on the ornamentation of the surface of their spores.

The characteristics used to define four groups of Streptomyces isolates from soil are shown in Table 3. The antibiotic-sensitivity patterns of strains from each of these groups are given in Table 4. It is evident that isolates grouped on their colour characteristics and melanin reaction had very similar antibiotic-sensitivity spectra. The only differences in the reactions of strains within a group were in the sizes of zone produced. Results from the replicate tests of all strains are given in Table 5, and it is evident that replication was generally good.

\section{Table 5. Results from the replicate testing of Streptomyces with antibiotics in filter-paper discs}

$\begin{array}{lccc}\text { Antibiotics } & \begin{array}{c}\text { Conc. of } \\ \text { antibiotic } \\ \text { solutions } \\ (\mu \mathrm{g} . / \mathrm{ml})\end{array} & \begin{array}{c}\text { Replicate pairs } \\ \text { of strains having } \\ \text { the same } \\ \text { reaction }(\%)\end{array} & \begin{array}{c}\text { Replicate pairs } \\ \text { of strains having } \\ \text { a different } \\ \text { reaction }(\%)\end{array} \\ \text { Streptomycin sulphate } & 3 & 100 & 0 \\ \text { Erythromycin } & 150 & 90 & 10 \\ \text { Neomycin sulphate } & 3 & 97 & 3 \\ \text { Polymyxin B sulphate } & 60 & 95 & 5 \\ \text { Chlortetracycline HCl } & 50 & 92 & 8 \\ \text { Chloramphenicol } & 300 & 97 & 3 \\ \text { Viomycin sulphate } & 3 & 97 & 3 \\ \text { Novobiocin sodium } & 100 & 95 & 5\end{array}$

\section{DISCUSSION}

Tests used for the description of microbial taxa should satisfy the following requirements. The results should be unambiguous, being recorded as 'positive' or 'negative' whenever possible. The replication of results obtained under standardized conditions should be good, the test not being too sensitive to small variations in experimental procedure. Finally, it is essential that the results obtained should have diagnostic value. The potential value of antibiotic-sensitivity patterns as a taxonomic character for streptomycetes can be assessed from the results presented here.

By using each antibiotic at a suitable concentration, results of diagnostic value were obtained without considering the exact sizes of the inhibition zones. When diagnosis is based on a positive or negative response of the test micro-organisms, rather than small differences in size of inhibition zones, good replication of results is more easily attained; many factors can influence the size of inhibition zones. Also the reaction of the streptomycetes to some of the antibiotics used resulted in zones with ill-defined edges, making accurate measurement of size difficult.

Some workers (e.g. Krassilnikov \& Agre, 1964; Pridham \& Lyons, 1965) studied the sensitivity of streptomycetes to antibiotics by observing their reactions when grown in the presence of organisms known to produce antibiotics. When this method is used, no control over the concentrations of the antibiotics is possible and it must be remem- 
bered that some strains produce more than one antibiotic. The use of pure preparations of antibiotics would seem preferable.

The antibiotic-sensitivity patterns of streptomycetes correlated well with other taxonomic information. Strains previously grouped together by using a variety of other criteria had similar reactions to the antibiotics. Burkholder et al. (1954) and Okami (1956) found that sometimes strains which had been placed in the same species had different antibiotic-sensitivity patterns. This was occasionally noted in the present work, but differences were usually only in reactions to one or two antibiotics. Also it is unfortunately true that strains given the same name do not always have the same characteristics.

The results of detailed co-operative studies, reported by Gottlieb (1961) and by Küster (1961), indicated that many criteria previously used in descriptions of streptomyces species were unreliable. There is therefore a need for new ones to replace these. More reliable criteria are also needed if studies of overall similarity, using large numbers of characters, are to be successfully applied to the genus Streptomyces and other actinomycete genera. The results obtained here with antibiotic discs were of taxonomic value and could be included with other criteria for the characterization of species of the genus Streptomyces. The inclusion of other antibiotics at concentrations selected to give diagnostic results might increase the value of the results obtained.

I thank Mr F. L. Davies who isolated some of the streptomycetes and did experiments to characterize them and Mr P. Widden who made some of the preliminary tests. I am also grateful to Professor E. Küster who provided some of the named Streptomyces cultures.

\section{REFERENCES}

Burkholder, P. R., Sun, S. H., ANDERson, L. E. \& Ehrlich, J. (1954). Criteria of speciation in the genus Streptomyces. Ann. N.Y. Acad. Sci. 60, 102.

Cross, T., Lechevalier, M. P. \& Lechevalier, H. (1963). A new genus of the Actinomycetales: Microellobosporia gen.nov. J. gen. Microbiol. 31, 421.

FlaIG, W. \& KUTZNER, H. J. (1960). Beitrag zur Systematik der Gattung Streptomyces Waksman et Henrici. Arch. Mikrobiol. 35, 105.

GotTLIEB, D. (1961). An evaluation of criteria and procedures used in the description and characterisation of the streptomycetes. Appl. Microbiol. 9, 55.

HiLL, L. R. \& SilveSTRI, L. G. (1962). Quantitative methods in the systematics of Actinomycetales. III. The taxonomic significance of physiological-biochemical characters and the construction of a diagnostic key. G. Microbiol. $10,1$.

HÜTTER, R. (1962). Zur Systematik der Actinomyceten. 7. Streptomyceten mit blauem, blaugrünem und grünem Luftmycel. Arch. Mikrobiol. 43, 23.

Krassilnikov, N. A. (1958). The significance of antibiotics as a specific characteristic of actinomycetes and their determination by the method of experimental transformation. Čsklá Mikrobiol. $5,288$.

Krassilnikov, N. A. (1960). Taxonomic principles in the actinomycetes. J. Bact. 79, 65.

Krassilnikov, N. A. \& AGRe, N. S. (1964). On two new species of Thermopolyspora. Hindustan Antibiot. Bull. 6, 97.

KüsTER, E. (1961). Results of a comparative study of criteria used in the classification of the actinomycetes. Int. Bull. bact. Nomencl. Taxon. 11, 91.

KuTZNER, H. J. \& WAKSMAN, S. A. (1959). Streptomyces coelicolor Muller and Streptomyces violaceoruber Waksman and Curtis, two distinctly different organisms. J. Bact. 78, 528.

Lechevalier, H. A., Solotorovsky, M. \& MCDurmont, C. I. (1961). A new genus of the Actinomycetales: Micropolyspora gen.nov. J. gen. Microbiol. 26, 11.

MeLVILLE, T. H. (1965). A study of the overall similarity of certain actinomycetes mainly of oral origin. J. gen. Microbiol. 40, 309. 
OKAMI, Y. (1956). A study for classification of Streptomyces. On the S. lavendulae group, with reference to its immunological properties. G. Microbiol. 2, 63.

OKami, Y., HaShimoto, T. \& SuzUKI, M. (1960). Sensitivity of actinomycetes to antibiotics as a guide to identification. J. Antibiot. Tokyo 13, 223.

Prauser, H. (1964). Aptness and application of colour codes for exact description of colours of streptomycetes. Z. allg. Mikrobiol. 4, 95.

Pridham, T. G., Anderson, P., Folye, C., Lindenfelser, L. A., Hesseltine, C. W. \& Benedict, R.G. (1956/57). A selection of media for maintenance and taxonomic study of streptomycetes. Antibiotics A. 1956/7, p. 947.

Pridham, T. G. \& Lyons, A. J. (1965). Further taxonomic studies on straight to flexuous streptomycetes. $J$. Bact. 89, 331.

SHINOBU, R. (1958). Physiological and cultural study for the identification of soil actinomycete species. Mem. Osaka Univ. lib. Arts Educ. 7, 1.

ShIRLING, E. B. \& GotTlieb, D. (1966). Methods for characterization of Streptomyces species. Int. J. system. Bact. 16, 313.

TRESNER, H. D. \& BACKUS, E. J. (1963). System of color wheels for streptomycete taxonomy. Appl. Microbiol. 11, 335.

Waksman, S. A. \& Lechevalier, H. A. (1953). Sensitivity of Actinomycetales to isonicotinic acid hydrazide, compared with other synthetic and antibiotic antituberculosis agents. Am. Rev. Tuberc. pulm. Dis. 67, 261.

WAKSman, S. A. (1961). The Actinomycetes, vol. II. Baltimore: Williams and Wilkins Co.

Williams, S. T. \& DAVIES, F. L. (1965). Use of antibiotics for selective isolation and enumeration of actinomycetes in soil. J. gen. Microbiol. 38, 251. 